\title{
Tablets Educacionais: formação de professores e mudanças na aprendizagem
}

\author{
Mara Rosane Noble Tavares ${ }^{1}$, Luciane Magalhães Corte Real² \\ Instituto Federal do Rio Grande do Sul - IFRS/Secretaria de Educação - SEDUC- \\ $\mathrm{RS} / 1^{\mathrm{a} C R E} / \mathrm{NTE}^{1}$, \\ Universidade Federal do Rio Grande do Sul - UFRGS² \\ mara-tavares@seduc.rs.gov.br, lucrealegmail.com
}

\begin{abstract}
It is a cutout of a qualitative research that aims to investigate the changes caused by the inclusion of Tablets in the classroom. In this paper we addressed the formation of high school teachers conducted by NTE / Porto Alegre or the use of Tablets. Polls, questionnaires and interviews with teachers were held. As partial results were pointed out both educational difficulties as school structural to include these in the classroom.
\end{abstract}

\begin{abstract}
Resumo Trata-se de um recorte de uma pesquisa qualitativa que pretende investigar as mudanças provocadas pela inclusão dos Tablets em sala de aula. No presente artigo é abordada a formação de professores do ensino médio, realizada pelo NTE/Porto Alegre, para o uso dos Tablets. Foram realizadas enquetes, questionários e entrevistas com os professores. Como resultados parciais foram apontadas tanto dificuldades pedagógicas como estruturais da escola para a inclusão destes em sala de aula.
\end{abstract}

\section{Apresentação}

No presente artigo é apresentado um recorte dos resultados de um projeto de pesquisa que tem como sujeitos os professores de Ensino Médio da Rede Pública Estadual que participaram das formações para o uso dos Tablets Educacionais a partir do Núcleo de Tecnologia Educacional Estadual da Cidade Porto Alegre - SEDUC-RS/1 ${ }^{\text {a }}$ CRE/NTE, realizado na Universidade Federal do Rio Grande do Sul, Faculdade de Educação, no período de 2013 a 2014.

A questão de pesquisa buscou responder quais as mudanças provocadas pela inclusão dos Tablets em sala de aula? Se há mudanças em relação à prática pedagógica e na posição de professor e de aluno. Os objetivos da investigação visam apontar os impactos que as formações realizadas pelos professores no NTE causaram em suas escolas de origem, em nível de direção, de professores, de funcionários, de alunos e da comunidade escolar; identificar como as formações realizadas no NTE se desdobraram em projetos com o uso das TIC, quais os critérios que os professores usaram para desenvolvê-los; a maneira como são encaminhados junto aos alunos; e, compreender como professores e alunos se envolvem e participam dos projetos com o uso de TIC.

A pesquisa dividiu-se em três fases, sendo as duas primeiras concomitantes: 1) Estado da arte - levantamento de pesquisas e relatos de experiências - anos de 2010 a 2013 - no Brasil que envolvam o uso de Tecnologias Móveis em Escolas de Ensino Básico. Vários pesquisadores investigam o uso de dispositivos móveis aliados a metodologias inovadoras como prática educativa para a construção de aprendizagens: 


\section{CBIE-LACLO 2015}

Anais dos Workshops do IV Congresso Brasileiro de Informática na Educação (CBIE 2015)

Bittencourt et al (2011); Real et al (2011; 2012); Real e Tavares (2012); Arantes et al (2012); Heinrich (2012); Moran (2013), Monteiro, Nunes e Reategui (2013); Real et al (2014, 2015) no qual este estudo encontra apoio; 2) Acompanhamento das formações, avaliação e levantamento de professores utilizando os Tablets educacionais; 3) tabulação dos dados, análise e expressão dos resultados.

A aprendizagem só acontece no momento em que o aluno compreende a utilidade e aplicação daquilo que é proposto. Com o uso dos Tablets o significado é compreendido pelo aluno na medida em que este aprende interagindo com o dispositivo e com seus pares, utilizando esses novos conhecimentos para fazer intervenções cada vez mais complexas. A aprendizagem com o uso dos Tablets se reveste da intencionalidade de provocar no aluno o processo de aquisição e interpretação da realidade usando-os para realimentar o processo de investigação e experimentação. Por exemplo, em uma investigação sobre dispositivos móveis usados como ferramentas na educação, Heinrich (apud REAL, TAVARES E PICETTI, 2013) demonstrou o impacto desses recursos na aprendizagem dos alunos, na geração de mudanças pedagógicas e no próprio desenvolvimento do sujeito. Verificou-se a aceitação da tecnologia móvel pelos alunos e uma influência positivamente significativa na motivação, na capacidade de pesquisar, trabalhar colaborativamente e comunicar os resultados construídos.

\section{Contexto da Experiência}

Um forte movimento político e acadêmico para incluir as Tecnologias da Informação e Comunicação - TIC na Educação está acontecendo, são inúmeras as experiências e o conhecimento construído nesse sentido nas últimas duas décadas.

Em 1997 foi criado o Programa Nacional de Informática na Educação (ProInfo), vinculado à Secretaria de Educação a Distância (SEED) do Ministério da Educação e Cultura (MEC). O Programa é responsável pela distribuição de equipamentos, implantação da Internet nas escolas, através dos diversos projetos que os estados e municípios aderem, e formação continuada de professores para o uso das TIC. O programa implantou os NTE em 27 Estados e Distrito Federal, em parceria com as Universidades Federais, capacitou seus Assessores de Tecnologia com Cursos de Especialização para atuarem nas Redes Públicas de Ensino, oferecendo formações e suporte às escolas para o uso das TIC (VALENTE, 1999, p.7).

Os dispositivos móveis são atualmente os principais instrumentos de modernização tecnológica da Rede Estadual de Ensino do Rio Grande do Sul. O uso da Tecnologia no Ensino Público é uma ação do ProInfo, que objetiva proporcionar a vivência dos professores e seus alunos com a linguagem da tecnologia digital garantindo acessibilidade com conectividade de Internet.

A SEDUC/RS é o órgão responsável por distribuir os dispositivos móveis no Estado e os NTE de cada cidade, pela formação para o uso pedagógico das tecnologias nas escolas. A introdução dos dispositivos móveis visa oferecer um suporte ao trabalho pedagógico e maiores oportunidades de apropriação da cultura digital, suas linguagens e raciocínios para todos envolvidos no processo educacional.

Os sujeitos pesquisados foram os professores de Ensino Médio que receberam os Tablets distribuídos pela SEDUC/RS e convocados pelo NTE/Porto Alegre para as formações técnico/pedagógicas, para seu uso em sala de aula, no período de abril de 2013 a setembro de 2014. 


\section{CBIE-LACLO 2015}

Anais dos Workshops do IV Congresso Brasileiro de Informática na Educação (CBIE 2015)

É relevante destacar que um dos pressupostos adotados pelos NTE é a construção de uma educação cidadã alcançada por meio de formações pedagógicas e não por treinamentos (REAL et al, 2013). Considera-se que não é suficiente instalar tecnologias nas escolas, também é necessário desenvolver espaços e tempos articulados com as Arquiteturas Pedagógicas ${ }^{1}$ (CARVALHO et al, 2007), para que as TIC não sejam usadas como substitutivas das ferramentas tradicionais. As tecnologias precisam ser encaradas como ferramentas de gerenciamento interdisciplinar, usadas pelo professor para planejar, administrar e construir colaborativamente com seus alunos e colegas.

\section{Quadro teórico: a questão da aprendizagem ou a construção da convivência em "rede"}

Os quadros teóricos de Jean Piaget e Humberto Maturana orientaram a coleta e análise dos dados.

Considera-se a "rede" uma construção coletiva que envolve cognição e afeto, uma construção com o outro (REAL, 2007).

Piaget (1972) diferencia aprendizagem do processo de desenvolvimento. O desenvolvimento do conhecimento é um processo espontâneo, ligado ao processo global da embriogênese. A embriogênese diz respeito ao desenvolvimento do corpo, do desenvolvimento do sistema nervoso e do desenvolvimento das funções mentais. $\mathrm{O}$ desenvolvimento é um processo que se relaciona com a totalidade de estruturas do conhecimento. Já, a aprendizagem é provocada por situações, por um experimentador psicológico; ou por um professor, com referência a algum ponto didático; ou por uma situação externa. Ela é entendida como oposta ao que é espontâneo. O desenvolvimento é o processo essencial e cada elemento da aprendizagem ocorre como uma função do desenvolvimento total em vez de ser um elemento que explica o desenvolvimento. Há alguns fatores que explicam o desenvolvimento: a maturação; a experiência, os efeitos do ambiente físico na estrutura da inteligência; a transmissão social em sentido amplo, a transmissão por linguagem, pela educação; e o processo de equilibração.

A experiência na educação/escola pode se mostrar uma experiência múltipla. Para algumas crianças, a escola é um dos primeiros espaços onde estabelecem relações com seus pares (entre sujeitos da mesma faixa etária). Logo, além de sua característica disciplinadora, a escola pode ser um forte agente socializador que permite uma pluralidade de vivências. Nesse sentido, na aprendizagem, aluno e professor podem se transformar na convivência. Porém, essa só pode ocorrer se ambos permitirem aprender, ou seja, se permitirem um perturbar o outro, desencadeando transformações que só poderão ser pensadas a partir de seus efeitos, ou seja, não podem ser planejadas com antecedência.

Alunos e professores, relativizando seu saber, abrem espaço para aprenderem juntos. Mas, certamente, cabe ao professor guiar os alunos no domínio explicativo de referência, construindo experiências que os capacitem a conhecer, operar e mesmo criticar os critérios de validação existentes no domínio escolar. Já, no caminho explicativo da objetividade-sem-parênteses, existe a pressuposição da existência de um caminho privilegiado que garanta acesso à verdade, no singular. Esse caminho é geralmente uma possessão de saber.

\footnotetext{
${ }^{1}$ Uso de diversas ferramentas, dinâmicas e metodologias, unidas para favorecer a aprendizagem.
} 


\section{CBIE-LACLO 2015}

Anais dos Workshops do IV Congresso Brasileiro de Informática na Educação (CBIE 2015)

Quando, numa conversação, muda a emoção, muda também o fluxo das coordenações de coordenações comportamentais consensuais e vice-versa. $O$ entrelaçamento do linguagear com o emocionar se estabelece na convivência, adquirindo uma estabilidade que gera consensualidades. Podemos observar redes de conversação que configuram relações hierárquicas baseadas no medo. Outras, que configuram relações mais heterárquicas, baseadas no amor. Se levarmos isso ao cotidiano das relações entre professores e alunos e entre os alunos, também podemos verificar que tais emoções condicionam posições frente à aprendizagem, facilitando-a ou dificultando-a. O emocionar define determinado encontro com o outro.

As diferentes emoções possibilitam e/ou interditam domínios de ações, tipos de comportamento. "Ao viver, fluímos de um domínio de ações a outro, num contínuo emocionar que se entrelaça com nosso linguagear" (MATURANA e ZÖLLER, 2004, p. 9).

A cultura é uma rede fechada de conversações. As mudanças culturais acontecem como modificações das conversações nas redes coloquiais em que vivem as comunidades que se modificam. Compreendemos a "sala de aula" como um espaço na escola que representa uma cultura local, com seu linguajar, suas recorrências, etc. As mudanças se sustentam mediante alterações no emocionar dos membros da comunidade. Nesse sentido, quanto pensamos na aprendizagem amorosa, trata-se de uma experiência que possibilita um emocionar na relação professor-aluno, alunos-alunos que se configura a partir da consideração do outro como legítimo outro. Um emocionar fundado na aceitação do outro.

Maturana (2001) propõe que necessitamos cuidar das emoções que estruturam o conversar entre professores e alunos. "Os meninos e meninas devem crescer na biologia do amor e não na biologia da exigência e da obediência" (p. 20). O respeito por si e pelo outro surge nas relações de aceitação mútua.

A aceitação do outro como legítimo outro na convivência não é um sentimento, é um modo de emocionar e, para Maturana, define a emoção amor. O amor é a emoção que se constitui nas ações de aceitação do outro como legítimo outro na convivência. Implica abrir espaço de interações recorrentes com o outro, no qual sua presença é legítima, sem exigências morais para participar de uma rede de conversação. A escola se constitui como um rico espaço de interações e de desafios em relação à aceitação do outro como legítimo outro.

Para Piaget (2001) a possibilidade de constituir um outro colaborativo depende de um percurso cognitivo-afetivo. Para Maturana (2002) esse percurso deriva da convivência em redes de conversação, cuja emoção que a constitui é a consideração da legitimidade do outro.

O desafio da proposta do NTE é a construção de redes possibilitando novas convivências, tanto presenciais quanto virtuais.

\section{A Estratégia Metodológica}

Trata-se de uma pesquisa qualitativa (MARTINS, 2008) na forma de estudo de caso que, segundo Yin (2010), é aconselhado para fenômenos reais dentro do contexto.

Os Sujeitos pesquisados foram mil seiscentos e sessenta professores de Ensino Médio que fizeram formações no NTE para a utilização dos Tablets em sala de aula. Os procedimentos previstos para a pesquisa obedeceram aos Critérios de Ética na Pesquisa 
com Seres Humanos, conforme Resolução no 196/96 do Conselho Nacional de Saúde. Mesmo não se beneficiando diretamente da pesquisa, os professores que aderiram contribuíram indiretamente para a compreensão do fenômeno estudado e para a produção de conhecimento científico.

A Estratégia Metodológica consistiu em observar um número de formações; aplicar questionários de avaliação sobre a formação e apurar como os dispositivos estavam sendo usados por alguns professores em sala de aula. Na primeira etapa da investigação são apresentadas as ações com suas avaliações e na segunda, o levantamento por enquete sobre o uso dos Tablets em sala de aula e alguns relatos compartilhados pelo Facebook.

\section{Investigação e Análise}

Foram convocados no período de abril de 2013 a setembro de 2014, mil seiscentos e sessenta professores de Ensino Médio para receber o Tablete YPY10' e formação de oito horas, voltada para o uso educacional do dispositivo. Cento e sessenta e oito professores abriram mão do Tablete e trinta e quatro recusaram recebê-lo, conforme alguns motivos, listados abaixo:

"Não vejo aplicação pedagógica no dispositivo" - "não sei usar e não gosto de tecnologia” - "o uso do Tablet vai contra a lei que proíbe o uso de dispositivos móveis em sala de aula".

Cento e trinta e quatro professores receberam e devolveram o Tablete por motivos de exoneração ou aposentadoria; dezessete professores fizeram apenas o primeiro turno de formação; trinta e seis professores não apresentaram justificativa para não atenderem à convocação. A seguir, alguns aspectos relevantes da avaliação realizada com cento e dezesseis professores de trinta e nove escolas, noventa e cinco atendidos no NTE/Porto Alegre e vinte e um em suas próprias escolas. $\mathrm{O}$ formato das respostas ofereciam escolhas de 1 a 5, onde 1 demonstrava fraca concordância na resposta e 5, como sendo de forte concordância:

Tabela 1 - Avaliação da Formação para o uso dos Tablets Educacionais

\begin{tabular}{|c|c|c|c|c|c|c|c|c|c|c|c|c|c|c|}
\hline \multicolumn{4}{|c|}{ OBJETIVOS ALCANCADOS } & \multicolumn{6}{c|}{ RELEVÂNCIA DA FORMACÃO } & \multicolumn{5}{|c|}{ UTILIZACÃo PROFISSIONAL } \\
\hline 1 & 2 & 3 & 4 & 5 & 1 & 2 & 3 & 4 & 5 & 1 & 2 & 3 & 4 & 5 \\
\hline $1 \%$ & $2 \%$ & $16 \%$ & $34 \%$ & $47 \%$ & $0 \%$ & $3 \%$ & $8 \%$ & $25 \%$ & $65 \%$ & $8 \%$ & $7 \%$ & $32 \%$ & $34 \%$ & $19 \%$ \\
\hline
\end{tabular}

Em uma primeira avaliação a maioria dos professores considerou que aprendeu a usar o Tablet, considerando um início para apropriação dessa tecnologia e que a formação foi importante para apontar uma direção e a construção de competências didático/pedagógicas. Contudo, em uma segunda avaliação, que apurava práticas com o uso do Tablet em sala de aula, no mesmo conjunto de professores, apenas quinze disseram usar o Tablet com seus alunos compartilhando, posteriormente, fotos e relatos de suas experiências com o NTE, pelo Facebook de suas escolas ou particulares.

$\mathrm{Na}$ segunda etapa da pesquisa, uma enquete sobre o grau de conforto dos professores quanto ao uso dos Tablets, foi enviada em duas listas para os endereços eletrônicos (e-mails) dos mil seiscentos e sessenta professores de Ensino Médio da Rede Pública, constantes no mailing do NTE. Mil seiscentos e seis professores confirmaram o recebimento, entretanto apenas sessenta e um professores responderam à enquete até $\mathrm{o}$ encerramento em 27/10/2014. 


\section{CBIE-LACLO 2015}

Anais dos Workshops do IV Congresso Brasileiro de Informática na Educação (CBIE 2015)

A enquete apurou alguns dados importantes, como o tempo de docência dos entrevistados, que varia de um ano a trinta e seis anos. Quarenta professores possuem menos de vinte anos de experiência em sala de aula. A carga horária de serviço varia de 40 a 60 horas semanais e muitos professores atuam em mais de uma modalidade de ensino ao mesmo tempo, alguns professores atuam em sala de aula e em setores educacionais.

\section{Gráfico 1 - Níveis de ensino em que os Professores atuam}

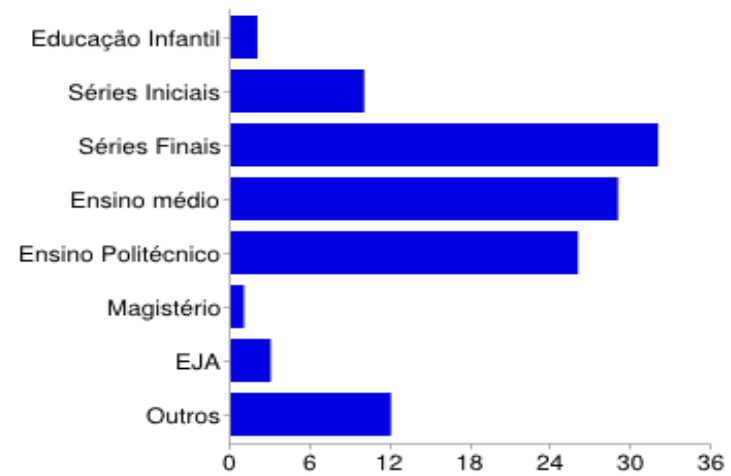

Quanto aos recursos tecnológicos oferecidos pela escola para a prática docente e os usados pelos professores em suas aulas a pesquisa aponta:

Tabela 2 e Gráficos 2 e 3 - Tecnologias oferecidas pelas Escolas X Tecnologias usadas pelos Professores em Sala de Aula

\begin{tabular}{|l|c|c|c|c|}
\hline \multicolumn{1}{|c|}{ SERVICO } & \multicolumn{2}{c|}{ OFERTA ESCOLA } & \multicolumn{2}{c|}{ USO EM AULA } \\
\hline Conectividade coma internet & 42 & $69 \%$ & 39 & $64 \%$ \\
\hline LABIN & 49 & $80 \%$ & 27 & $44 \%$ \\
\hline Sala de Vídeo & 52 & $85 \%$ & 44 & $72 \%$ \\
\hline Biblioteca Informatizada & 10 & $16 \%$ & 4 & $7 \%$ \\
\hline Notebook e Datashow & 47 & $77 \%$ & 37 & $61 \%$ \\
\hline Proietor Multimidia e Lousa Digital & 25 & $41 \%$ & 13 & $21 \%$ \\
\hline Netbooks (Um por ume LaboratórioMóvel) & 16 & $26 \%$ & 8 & $13 \%$ \\
\hline Câmeras Digitais & 21 & $34 \%$ & 19 & $31 \%$ \\
\hline Celulares: & 0 & 0 & 26 & $43 \%$ \\
\hline Tabletes: & 0 & 0 & 20 & $33 \%$ \\
\hline Nenhum recurso & 0 & 0 & 4 & $7 \%$ \\
\hline Outros não especificados & 5 & $8 \%$ & 3 & $5 \%$ \\
\hline
\end{tabular}

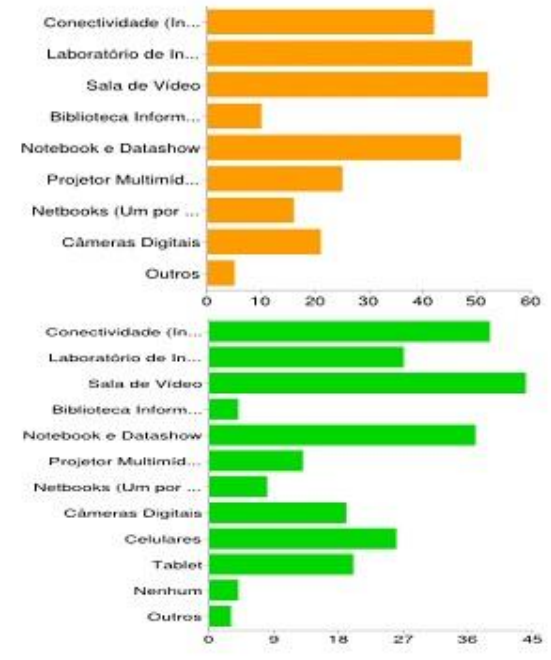

Com relação ao planejamento de aulas com o uso do Tablet:

Gráficos 4 e 5 - Uso e Frequência do uso dos Tablets em Sala de Aula

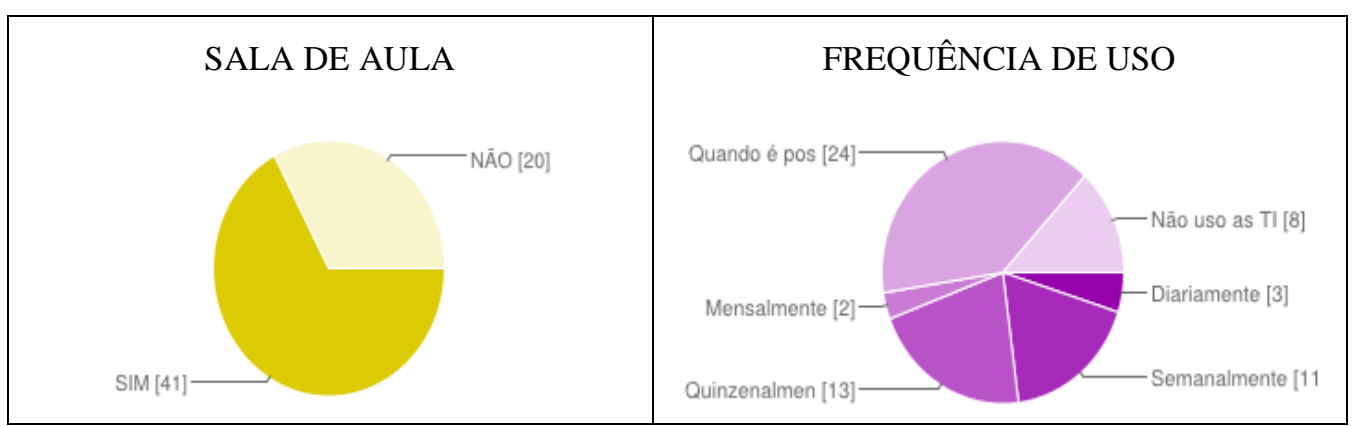


Questionados quanto ao grau de dificuldade para planejar e aplicar uma aula com o uso do Tablet, vinte e cinco professores responderam não encontrar dificuldades e trinta e seis demonstraram encontrar dificuldades em relação à aplicação, e afirmaram não planejar por causa de fatores limitadores encontrados na estrutura das escolas, como:

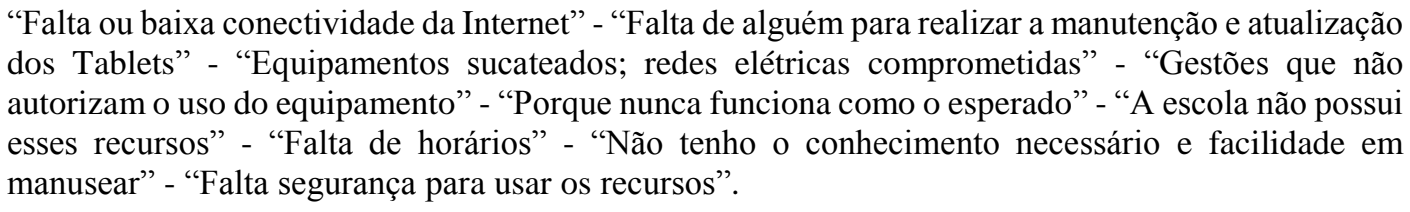
dos Tablets" - "Equipamentos sucateados; redes elétricas comprometidas" - "Gestões que não autorizam o uso do equipamento" - "Porque nunca funciona como o esperado" - "A escola não possui esses recursos" - "Falta de horários" - "Não tenho o conhecimento necessário e facilidade em manusear" - "Falta segurança para usar os recursos".

Vinte e sete professores avaliaram positivamente as aulas e o processo de aprendizagem com o uso dos Tablets, consideraram o trabalho mais produtivo e os alunos mais interessados, entre outros argumentos; embora, alguns professores observem que os alunos aprendam menos do que deveriam nas aulas tradicionais. Trinta e três professores repetiram que os fatores limitadores para o uso dos Tablets são: $1^{\circ}$ ) falta de segurança nas escolas; $2^{\circ}$ ) precariedade dos equipamentos oferecidos; e $3^{\circ}$ ) os paradigmas educacionais vigentes.

Há mudanças observadas pelos professores a partir do uso dos Tablets, embora a maioria, quarenta e cinco professores, identifique mudanças em sua prática pedagógica, vinte e seis professores não as observam.

"Não, porque não uso Ainda" - "Uma mudança concreta ainda não, por falta de condições, mas a minha mentalidade mudou muito" - "Percebo uma mudança em meu pensar, mas que ainda não se dirige à prática" - "Só uso o Tablet e os celulares para jogarem e eles adoram" - "Os alunos estão habituados com aulas tradicionais" - "Poderia usar muitos outros recursos em sala de aula se a escola oferecesse".

As respostas dos professores entrevistados sobre o que falta para a apropriação e uso dos Tablets como ferramenta pedagógica foram categorizadas em três grupos: $1^{\circ}$ ) aqueles que identificam a necessidade de capacitação profissional desde o início da formação, ou a necessidade de atualização profissional; $2^{\circ}$ ) os que, além de formação, apontam para a necessidade de tempo, interesse, mudança de paradigma na educação e planejamento com os pares, conforme a realidade de cada escola; $3^{\circ}$ ) respostas listando os elementos que concorrem como complicadores para não adotar os Tablets e as TIC como ferramenta pedagógica.

\section{Considerações Finais}

Apesar do baixo número de retorno dos professores, alguns elementos apresentaram relação de recorrência no mapeamento, aparecendo mais de uma vez nas respostas dos professores a uma mesma questão e em questões diferentes.

Menos de $8 \%$ dos professores, que receberam os Tabletes e realizaram a formação completa, avaliaram a formação; $3 \%$ dos professores atendidos aceitaram o convite para responder a enquete sobre o uso dos Tablets em Sala de Aula e menos de 1\% enviaram práticas usando os Tablets com seus alunos.

Os números apresentados permitem supor que o processo de adoção e inclusão do uso dos Tablets, na rotina escolar, não acontece com facilidade. Os professores marcaram ora usar, ora não usar o Tablet em sala de aula, nas diferentes categorias pesquisadas, apontaram como causas vários fatores impeditivos para a adoção do seu uso no contexto escolar: falta de vontade política; equipamentos de baixa qualidade; falta de internet; de técnicos e coordenadores de informática; de tempo; de conhecimentos específicos; de interesse dos gestores; de atenção dos alunos. Os professores também se queixam que os 


\section{CBIE-LACLO 2015}

Anais dos Workshops do IV Congresso Brasileiro de Informática na Educação (CBIE 2015)

alunos gostam de aulas tradicionais; que só gostam de jogar; de acessar redes sociais; etc. A baixa adesão à pesquisa, de um modo geral, também pode indicar a dificuldade dos professores para lidar com a inclusão das diferentes tecnologias na educação.

As tecnologias afetam a educação, mas não chegam a saturá-la totalmente, porque ela está contida a lugares e tempos determinados, como a escola, a sala de aula, o calendário escolar, a grade curricular. Os professores apresentam como condição para o uso dos Tablets e a adoção de práticas com as TIC no espaço escolar, uma boa conectividade com a internet, espaços bem equipados e de qualidade, assistência técnica, apoio da coordenação pedagógica, gestão escolar interessada e capacitação. Valente (1999) destaca a necessidade de alterar o espaço escolar, desde sua organização até as relações que se estabelecem entre aluno, professor e conhecimento. Enfatiza que a mudança pedagógica desejada está na passagem da educação centrada na transmissão da informação e da instrução para a criação de ambientes de aprendizagem, onde realmente ocorra a construção do conhecimento por parte dos alunos.

Diaz (2012 apud REAL, TAVARES E PICETTI, 2013), considera importante investigar as dinâmicas nos espaços educativos, aponta que a introdução das tecnologias na educação necessita de uma ação detalhada e programada para formação dos educadores. Para o pesquisador, os professores necessitam receber uma formação de qualidade para melhor explorar as tecnologias, que possuem funções educativas em si mesmas. Moran (2000), também aponta a necessidade de se investir na formação de professores, para que as transformações pedagógicas almejadas superem as dificuldades da mudança. $\mathrm{O}$ autor ressalta que o uso das TIC na educação pode proporcionar processos de comunicação participativos, tornando a relação professor-aluno mais aberta e interativa. A aula não é um espaço determinado, mas tempo e espaço contínuos de aprendizagem que podem ser caracterizados por diferentes estilos de professores e alunos, tecnologias e conteúdos. O importante é aprender e não definir padrões para o ensinar.

A escola usa instrumentos, práticas e metodologias antigas, incapazes de envolver os alunos, não só por causa da precariedade de suas instalações, falta de equipamentos, qualificação, tempo e segurança, mas porque muitos professores não acreditam que aliar a tecnologia às práticas pedagógicas criem propostas desafiadoras, capazes de envolver seus alunos; há os professores que acreditam que a escola não precisa mudar suas práticas, porque deixaria de cumprir o papel para o qual foi criada, expressão maior de paradigmas tradicionais da educação. Com dificuldade a escola cria espaços de autoria, porque sua função é educar, por sua vez, empurra o aprender para um segundo plano. Um dos principais desafios contemporâneos para a educação é tornar a escola um centro de aprendizagem, que transforma as informações importantes, entre tantas, em conhecimentos, de tal forma que façam parte do referencial do aluno. Aprendemos melhor quando vivenciamos, relacionamos, experimentamos, sentimos aquilo que aprendemos, estabelecendo vínculos, dando significado a um novo contexto para integrá-lo ao que conhecemos (MORAN, 2013).

Integrar as TIC à educação é um processo complexo, requer mais do que a soma da distribuição de equipamentos como os Tablets, da formação, da análise das novas formas de ensinar, aprender e se relacionar com o conhecimento e o mundo; exige que aconteçam mudanças importantes de paradigma e estrutura, na formação dos professores, nos espaços físicos e distribuição dos tempos escolares. A tarefa de preparar os professores para utilizar as TIC, muitas vezes, não consegue vencer o desafio que o seu uso na sala de aula representa. Com base nos dados mapeados, verifica-se, a partir das formações pedagógicas realizadas no NTE, a necessidade de construção de redes, com as Universidades, através da adoção das TIC nos Cursos de Licenciatura, com profissionais 


\section{CBIE-LACLO 2015}

Anais dos Workshops do IV Congresso Brasileiro de Informática na Educação (CBIE 2015)

de diferentes campos de estudo que se ocupam da Aprendizagem e da Educação, com os setores de Logística das CRE e da própria SEDUC/RS com órgãos e empresas; enfim, com todas as entidades que podem movimentar as mudanças educacionais, de paradigma ou estruturais, necessárias para atender as demandas, que a inclusão pedagógica das TIC produzem nas escolas.

A partir das experiências positivas dos professores que usam os Tablets em aula com seus alunos, percebemos as mudanças provocadas pela inclusão dos Tablets em sala de aula, observamos que ao planejar aulas com o uso das TIC, associadas à Internet, criam-se intensas possibilidades de formação de redes de interação social, quase instantâneas, para construir conhecimentos (DORIGONI e SILVA, 2003), os professores passam a usar metodologias que respeitam os diferentes ritmos de aprendizagem, criam redes de conversação e espaços de autoria para que os alunos construam e revejam suas hipóteses, com autonomia; desvinculam o aprender da relação acerto e erro, elementos importantes no processo contínuo de aprendizagem; observa-se a mudança na qualidade afetiva das relações estabelecidas entre professores e alunos e o rompimento com o fenômeno do fracasso escolar (TAVARES e REAL, 2011).

\section{Referências}

Arantes, Flávia Linhalis et al. Laptops Educacionais em Escolas Públicas: Primeiros Resultados de uma Abordagem Socio-técnica. Revista Brasileira de Informática na Educação, [s.1.], v. 20, n. 2, p.31-32, 22 ago. 2012. Comissão Especial de Informática na Educação. DOI: 10.5753/rbie.2012.20.2.31. Em: <http://brie.org/pub/index.php/rbie/article/view/1346>.

Bittencourt, Juliano; Kist, Sílvia; Tatizana, Décio; Schafer, Patrícia; Fagundes, Léa (2011). Ambientes virtuais de aprendizagem na modalidade 1:1: um estudo de caso sobre o AMADIS na Fase I do Programa UCA. RENOTE - Revista Novas Tecnologias na Educação, Porto Alegre, v. 9, n. 2.

Caravalho, M.J. S.; Menezes, C.S. \& Nevado, R.A. (2007). Arquiteturas Pedagógicas para Educação a Distância: concepções e suporte telemático. In: Simpósio Brasileiro de Informática na Educação, Juiz de Fora - MG. Em: <http://arquiteturaspedagogicas. pbworks.com/f/Arquiteturas_Pedagogicas.pdf $>$

Dorigoni, Gilza Maria Leite; Silva, João Carlos da (2003). Mídia e Educação: o uso das novas tecnologias no espaço Escolar. <http://www.diaadiaeducação.pr.gov.br/portals/pde/ arquivos -1170-2.pdf>

Martins, G. A. Estudo de caso: uma estratégia de pesquisa. $2^{\mathrm{a}}$ ed. São Paulo: Atlas, 2008.

Maturana, Humberto R. (2001). Cognição, ciência e vida cotidiana. Organização e tradução Cristina Magro, Victor Paredes. - Belo Horizonte: Ed. UFMG, 203p. (Humanitas). Em: <https://sites.google.com/site/livrosdamara/home/autores/ educacao/humberto-maturana $>$

Maturana, Humberto R.; Rezepka, S. N. (2002). Formação e capacitação humana. Petrópolis: Vozes, 2002

Maturana, Humberto R.; Verden-zöller, G. (2004). Amar e brincar: fundamentos esquecidos do humano. São Paulo: Editora Palas Athena, 2004.

Monteiro, Francisca Keyle de Freitas Vale; Nunes, Walter Cezar; Reategui, Eliseo (2013). Pedagogia das Mídias Interativas: empreendendo EDUROAM-Br para dispositivos móveis com interfaces de equanimidade. X Esud, Belém do Pará, v. 2, n. 


\section{CBIE-LACLO 2015}

Anais dos Workshops do IV Congresso Brasileiro de Informática na Educação (CBIE 2015)

10, p.1-10, jun. 2013. Anual. Em: <http://www.aedi.ufpa.br/esud/ trabalhos/oral/AT1/114060.pdf>.

Moran, José (2000). Mudar a forma de ensinar e de aprender. Publicado inicialmente na Revista Interações, São Paulo, 2000. vol. V, p.57-72

Moran, José (2013). Caminhos que facilitam a aprendizagem. "Novas Tecnologias e Mediação Pedagógica", Papirus, $21^{\text {a }}$ ed., 2013, p. 27-29.

Moran, José (2013). Tablets para todos conseguirão mudar a escola? - Pesquisador e orientador de projetos inovadores na educação - Do livro "Novas Tecnologias e Mediação Pedagógica", Papirus, 21a ed., 2013, p.30-35 (texto ampliado) Em: < http://www2.eca.usp.br/moran/wp-content/uploads/2014/03/Tablets.pdf>

Piaget, Jean. (1972). A Evolução Intelectual da Adolescência à Vida Adulta. Trad. Fernando Becker e Tania B.I. Marques. Porto Alegre: Faculdade de Educação, 1993. Traduzido de: Intellectual Evolution from Adolescence to Adulthood. Human Development, v. 15, p. 1-12, 1972.

Piaget, Jean (2001). Seis Estudos de Psicologia. Rio de Janeiro: Forense Universitária, 2001. 136p.

Real, Luciane Magalhães Corte (2007). Aprendizagem amorosa na interface Escola, Projetos de Aprendizagem e Tecnologias Digitais. Tese de Doutorado, PGIE/UFRGS.

Real, Luciane Magalhães Corte; Picetti, Jaqueline dos Santos (2011). Aprendizagens por possibilidades de deslocamentos em um Laboratório de Informática: um estudo de caso no Ensino Fundamental. In: $22^{\circ}$ Simpósio Brasileiro de Informática na Educação, 2011, Aracaju. Anais do XXII SBIE - XVII WIE, v. Trilha. p. 1-4.

Real, Luciane Magalhães Corte; Tavares, Mara Rosane Noble (2012). Alunos do Ensino Fundamental e professores construindo espaços de Educação a Distância na Escola. In: 23 Simpósio Brasileiro de Informática na Educação, Congresso Brasileiro de Informática na Educação, 2012, Rio de Janeiro. Anais do XXIII CBIE - XVIII WIE $2012 \mathrm{em}$ : http://www.br-ie.org/pub/index. php/wie/article/view/2086

Real, Luciane Magalhães Corte; Tavares, Mara Rosane Noble; PICETTI, Jaqueline dos Santos (2013). Formação de Professores para o Uso Educacional de Tablets no Ensino Médio: possíveis mudanças na prática pedagógica. In: Workshop do II Congresso Brasileiro de Informática na Educação, 2013. v. CBIE 2.

Tavares, Mara Rosane Noble; Real, Luciane Magalhães Corte (2011). ARQUITETURAS PEDAGÓGICAS: As relações construídas no processo de aprendizagem mediado por computador. Anais do IX Congresso Internacional de Tecnologia na Educação, v. 9, p. 1-15, 2011.

Valente, José Armando (1999). O computador na sociedade do conhecimento. Campinas, SP: UNICAMP/NIED, 1999. 156p.

Yin, Robert K. (2010) Estudo de caso: planejamento e métodos. Porto Alegre, Bookman. 